\title{
PERCEPÇÕES SOBRE O SETOR EDUCACIONAL DO MERCOSUL E SUA ATUAÇÃO VISANDO À INTEGRAÇÃO ENTRE PAÍSES POR MEIO DA EDUCAÇÃO SUPERIOR UNIVERSITÁRIA
}

\author{
PERCEPTIONS ABOUT THE MERCOSUR EDUCATIONAL SECTOR AND ITS \\ ACTIVITIES TOWARD THE INTEGRATION AT THE UNIVERSITY-LEVEL
}

\author{
Rita de Cássia Marques Lima de Castro ${ }^{(*)}$ \\ Universidade de Mogi das Cruzes, São Paulo (SP), Brasil
}

\begin{abstract}
Resumo: Mediante revisão bibliográfica e questionário via web, este artigo apresenta uma análise da atuação do Setor Educacional do MERCOSUL (SEM) com foco na integração de países pela Educação Superior Universitária. Embora haja diversas tentativas do MERCOSUL visando à maior integração, constata-se que: (i) houve menos avanços no setor terciário universitário que em outros níveis; (ii) há diferenças significativas sem reconhecer o papel do SEM ao se comparar as respostas do grupo I - Argentina, Paraguai e Uruguai, com maior índice de respostas favoráveis, e os do grupo II - Brasil, onde também é maior o nível de desconhecimento sobre o tema.
\end{abstract}

Palavras-chave: Setor Educacional do MERCOSUL; Educação Superior Universitária; Tratados Internacionais.

Abstract: Through literature review and a web questionnaire, this paper presents a performance analysis of MERCOSUR Education Sector (MES) focusing the countries integration through Higher Education. Although several MERCOSUR attempts have been made to seek greater integration between countries, it is noted that: (i) there have been fewer advances in the university tertiary sector than in other sectors; (ii) there are significant differences between countries concerning the role of SEM;. Comparing the responses of group I - Argentina, Paraguay and Uruguay with group II - Brazil, we found a higher rate of positive responses in the former than in the latter. .

Keywords: Mercosur Educational Sector; Higher Education; International Treaties.

(*) Doutora, Professora da Universidade de Mogi das Cruzes - Campus Villa-Lobos; atua na área de apoio institucional de pesquisa no Instituto de Ensino e Pesquisa (INSPER).E-mail: <ritalimadecastro@gmail.com>.Recebidoem 14.10.2014, aceito em: 05.12.2014. 


\section{INTRODUÇÃO}

As aspirações de integração da América Latina derivam de longa data. Pode-se considerar que desde a época das independências dos diversos Estados latino-americanos essas aspirações reverberavam em atores-pensadores da América Latina, como Simón Bolívar ou José Martí. No final de 1700, já se registra a luta de Bolívar pelo primeiro tratado de união latino-americana, o chamado Tratado de União, Liga e Confederação Perpétua entre as Repúblicas da Colômbia, Centro-América, Peru e Estados Unidos.

No início do século XX, a história dos governos brasileiros registra as negociações para integração entre alguns países da América do Sul, na condução de Campos Sales. Em 1947, realiza-se o Tratado Interamericano de Assistência Recíproca (TIAR) e, no ano seguinte, a CEPAL é fundada. Nos anos 1960, realiza-se o Tratado de Montevidéu e a criação da Associação Latino-Americana de Livre-Comércio (ALALC), entre Argentina, Brasil, Paraguai, Uruguai, Chile, México, Peru. Também se firma o Acordo de Cartagena, mais conhecido como Pacto Andino, entre Bolívia, Chile e Colômbia. Posteriormente, nos anos 1980, novo Tratado de Montevidéu substitui a ALALC pela Associação Latino-Americana de Integração (ALADI) e Argentina e Brasil firmam protocolos bilaterais de integração e cooperação econômica (ALMEIDA, 1996; COSTA, 2003; GONÇALVES, 2012).

Em 26 de março de 1991, ocorre a assinatura do Tratado de Assunção, que constitui o Mercado Comum do Cone Sul (MERCOSUL) e, dentre outras medidas, a criação do Setor Educativo do MERCOSUL. Cabe lembrar que, em 19 de janeiro de 1995 ocorrem a implantação efetiva da União Aduaneira e a definição da estrutura institucional do MERCOSUL, pelo Protocolo de Ouro Preto, considerado como sua fonte jurídica primária (ALMEIDA, 1996; COSTA, 2003).

Considerando-se o escopo e propósito deste artigo, será abordado, especificamente, o papel do Setor Educacional do MERCOSUL, mas, para tanto, é oportuno levar em consideração alguns aspectos político-econômicos e remontar à criação da Associação Latino Americana de Integração (ALADI) que, em 1980, substituiu a Associação Latino-Americana de Livre-Comércio (ALALC), para depois, chegar-se ao MERCOSUL.

A ALADI foi considerada como uma instituição mais aberta pelo fato de possibilitar a atuação de países não membros em ações de comércio, bem como trabalhar em ações de cooperação horizontal nos países consignados, à época, em vias de desenvolvimento. O que cabe observar foi a contradição existente naquele momento, que consistia em, de um lado, o estímulo à abertura comercial e as forças do sistema multilateral de comércio seguindo nessa direção; e de outro, a contração dos países em desenvolvimento, em especial da América Latina, que se fechavam seguindo o modelo da CEPAL de estímulo à produção interna e não abertura ao mercado externo. Sustentava essa maior cautela comercial o acordo até então existente, a Associação Latino-Americana de Livre-Comércio - ALALC, que pode ser considerado como um modelo deveras conservador em termos de abertura de mercado, no qual cada produto era objeto de longas negociações.

Em verdade, até as eleições de Ronald Reagan e Margaret Thatcher, não se sabia, de fato, que modelo a economia iria tomar, mas com a vitória desses dois 'baluartes' do 
liberalismo, o incentivo à abertura de mercados volta a ganhar corpo, e o novo acordo - ALADI, que veio a substituir a ALALC - representa muito bem esse momento de transição, trazendo propostas de flexibilização do modelo.

Ocorre que a flexibilização deveria não somente permitir a abertura de mercados, mas também - e principalmente - contribuir para que os que ingressassem no acordo pudessem se desenvolver economicamente. Muitos países, em especial os de menor desenvolvimento relativo, como Paraguai e Uruguai, por exemplo, tinham receio em abrir totalmente sua economia e a todos os países. Neste ponto, a ALADI trazia, em sua flexibilização do modelo, mecanismos que permitiam a celebração de acordos de alcance parcial, o que possibilitaria a um país realizar acordos com outro que tivesse economia mais assimétrica ou complementar, sem estender esse mesmo acordo a outros países signatários do acordo que fossem mais ameaçadores economicamente, por terem economias mais semelhantes e competirem nos mesmos nichos.

Observa-se, portanto, que a permissão desses acordos de alcance parcial representa a não aplicação do princípio da discriminação (art. ํㅡㄹ do GATT, incorporado com a criação da $\mathrm{OMC}$ ), conhecido como o relativo ao Tratamento Geral de Nação Mais Favorecida. O MERCOSUL teve sua formação estabelecida com base na Cláusula de Habilitação, fundamento sobre o qual foi, inclusive, apresentado ao GATT, em 1992. É interessante verificar que, nesse mesmo ano, as delegações dos Estados Unidos e outras partes contratantes do GATT solicitaram a notificação do MERCOSUL com base no Art. XXIV do GATT. A notificação apresentada ao GATT com relação ao Tratado de Assunção com base na Cláusula de Habilitação pode ser considerada estratégica, visto que os países que realizam acordos sob a égide dessa cláusula não necessitam liberar o essencial de seu comércio, nem estender as preferências incondicionalmente.

Destaque-se o fato de o MERCOSUL ser um acordo de alcance parcial que, como praticamente todos os acordos efetuados no início da década de 1990, sofreu a influência do Consenso de Washington, o qual trouxe a sua cartilha da liberalização no contexto internacional. O MERCOSUL não ficou, pois, imune a essa influência e o acordo firmado entre Argentina, Brasil, Paraguai e Uruguai (primeiros países signatários), tendo Bolívia, Chile, Colômbia, Equador e Peru como países associados (MENEZES, 2006), trouxe a clássica definição de mercado comum em seu bojo, com a criação da zona de livre-comércio e uma meta bem ambiciosa de ter, em três anos, todas as tarifas de comércio da região 'zeradas'. Com raras exceções, o acordo conseguiu, em 1994, ter praticamente $70 \%$ do todo proposto já em andamento.

A ideia de acordos regionais pressupõe um avanço para etapas superiores de integração comercial. Se no início do tratado, em 1991, não se quis dar uma conformação institucional definitiva, esta veio em 1994, com a assinatura do Protocolo de Ouro Preto. O Tratado de Assunção foi modificado, concretizando-se a união aduaneira, com uma Tarifa Exterior Comum (TEC) implantada para os quatro países que compõem o acordo (Argentina, Brasil, Paraguai e Uruguai).

O Protocolo de Ouro Preto foi importante porque estabeleceu o MERCOSUL como uma união aduaneira e como uma instituição com personalidade jurídica internacional, isto é, uma instituição que pode assinar acordos internacionais. É importante frisar, 
porém, que, apesar de o processo inicial ter cumprido grande quantidade das metas estabelecidas, algo raro de acontecer em questões dessa natureza, as controvérsias permaneceram e foi necessário criar um mecanismo para solucioná-las. Isto foi feito mediante a criação, em novembro de 1991, de um Órgão de Solução de Controvérsias, um Conselho Comum de Mercado e outros órgãos, mediante assinatura do Protocolo de Brasília. Outro importante documento foi o Protocolo de Olivos, assinado em 2002, para solução de controvérsias.

Algumas questões perpassam esse breve histórico: será o MERCOSUL um novo regionalismo, com visões além da econômica, atraindo investidores estrangeiros, desenvolvendo o comércio intrarregional e buscando paz, democracia e participação efetiva em fóruns internacionais, na definição de Devlin e Estevadeordal (2001), ou será o MERCOSUL moldado no antigo regionalismo, em que as negociações para liberalização do comércio crescem modestamente e de forma limitada? Para esses autores, o MERCOSUL estrutura-se nessa visão de novo regionalismo porque, além de desenvolver o comércio inter-regional e atrair investidores de fora, pode estabelecer acordos com nações desenvolvidas, visando à maior integração.

Integração, palavra importante e complexa, relembrando o dizer de Celli Junior (2006), por se tratar de um fenômeno que também é político, além de econômico e jurídico. Será o MERCOSUl um acordo que visa a esta integração? Para Menezes (2006), o MERCOSUL é "uma organização regional (...) de integração, de natureza intergovernamental, que se encontra entre uma zona de livre comércio incompleta e uma união aduaneira imperfeita, cujo objetivo central é chegar a um mercado comum" (MENEZES, 2006, p. 151).

Resumindo, e utilizando as palavras de Peña (2009), o MERCOSUL possui, sem dúvida, um caráter mais amplo do que o econômico, envolve objetivos políticos que demonstram as relações de poder entre os países que constituem o espaço geográfico do MERCOSUL e relaciona-se ao "predomínio da lógica de integração no espaço sul-americano" (PEÑA, 2009, p. 58). Por tudo isto, pode-se concluir que o MERCOSUL, em termos de liberalização do comércio, aparenta estar nos passos do caminho do multilateralismo, não sendo seus passos de regionalismo barreiras ao multilateralismo, mas, sim, estímulo a ele.

\section{ESTRUTURA DO MERCOSUL E DO SETOR EDUCACIONAL DO MERCOSUL}

O MERCOSUL tem personalidade jurídica de direito internacional, de acordo com o expresso no art. 34 do Protocolo de Ouro Preto, o que significa que o MERCOSUL possui "(...) existência própria, distinta dos Estados que o constituem" (AMARAL JUNIOR, 2008, p. 408); ou seja, como apresentado, o MERCOSUL pode realizar funções como as de negociação e assinatura de acordos com outros países, organizações internacionais e blocos de países. Sua estrutura está descrita no quadro 01.

Dentro desta estrutura, destaca-se o Conselho do Mercado Comum, visto que o Setor Educacional do MERCOSUL está a ele associado e subordinado. Vale ressaltar que 
o CMC é "(...) o órgão superior do MERCOSUL ao qual incumbe a condução política do processo de integração e a tomada de decisões para assegurar o cumprimento dos objetivos estabelecidos pelo Tratado de Assunção e para lograr a constituição final do mercado comum" (AMARAL JR., 2008, p. 409). Esta definição está estabelecida no art. 3ํ do Protocolo de Ouro Preto (MERCOSUL, 2014). Há, também, o envolvimento do GMC, pois este deve enviar, em todas as reuniões dos Ministros da Educação, um representante, a fim de que haja ações políticas mais integradas. Ressalte-se, outrossim, que apenas CMC, GMC e CCM (esta, nas Diretrizes) têm capacidade decisória.

\begin{tabular}{|c|c|c|c|c|}
\hline $\begin{array}{l}\text { ARTIGOS - } \\
\text { PROT. OURO } \\
\text { PRETO }\end{array}$ & ÓRGÃO & $\begin{array}{l}\text { PRINCIPAL } \\
\text { FUNÇÃO OU } \\
\text { ATRIBUIÇÃO }\end{array}$ & $\begin{array}{c}\text { QUEM } \\
\text { PARTICIPA }\end{array}$ & $\begin{array}{c}\text { PRONUNCIAMENTO } \\
\text { OCORRE POR MEIO } \\
\text { DE... }\end{array}$ \\
\hline 3 a 9 & $\begin{array}{l}\text { Conselho } \\
\text { do Mercado } \\
\text { Comum } \\
\text { (CMC) }\end{array}$ & $\begin{array}{l}\text { direção política, } \\
\text { tem capacidade } \\
\text { decisória }\end{array}$ & $\begin{array}{l}\text { Ministros das } \\
\text { Relações Exte- } \\
\text { riores e da Eco- } \\
\text { nomia, e outros } \\
\text { ministros, estes } \\
\text { quando convi- } \\
\text { dados }\end{array}$ & $\begin{array}{l}\text { Decisões, cujo cum- } \\
\text { primento é obrigatório } \\
\text { pelos Estados-partes }\end{array}$ \\
\hline 10 a 15 & $\begin{array}{l}\text { Grupo } \\
\text { Mercado } \\
\text { Comum } \\
\text { (GMC) }\end{array}$ & $\begin{array}{l}\text { órgão executivo } \\
\text { do MERCOSUL, } \\
\text { tem capacidade } \\
\text { decisória }\end{array}$ & $\begin{array}{l}\text { Representantes } \\
\text { dos Ministérios } \\
\text { das Relações } \\
\text { Exteriores, de } \\
\text { Economia e } \\
\text { dos Bancos } \\
\text { Centrais }\end{array}$ & $\begin{array}{l}\text { Resoluções, cujo } \\
\text { cumprimento é obri- } \\
\text { gatório pelos Estados- } \\
\text {-partes }\end{array}$ \\
\hline 16 a 21 & $\begin{array}{l}\text { Comissão } \\
\text { de Co- } \\
\text { mércio do } \\
\text { MERCOSUL } \\
\text { (CCM) }\end{array}$ & $\begin{array}{l}\text { órgão de consul- } \\
\text { ta e assessoria, } \\
\text { tem capacidade } \\
\text { decisória }\end{array}$ & $\begin{array}{l}\text { Membros indi- } \\
\text { cados - coorde- } \\
\text { nação feita pe- } \\
\text { los Ministérios } \\
\text { das Relações } \\
\text { Exteriores }\end{array}$ & $\begin{array}{l}\text { Diretrizes ou Propos- } \\
\text { tas, sendo apenas as } \\
\text { primeiras obrigatórias }\end{array}$ \\
\hline 22 a 27 & $\begin{array}{l}\text { Comissão } \\
\text { Parlamentar } \\
\text { Conjunta } \\
\text { (CPC) }\end{array}$ & $\begin{array}{l}\text { Órgão represen- } \\
\text { tativo dos parla- } \\
\text { mentares; atua no } \\
\text { sentido de forta- } \\
\text { lecer o vínculo } \\
\text { existente entre } \\
\text { o MERCOSUL e } \\
\text { os parlamentos } \\
\text { nacionais. Não } \\
\text { integra o "arca- } \\
\text { bouço institucio- } \\
\text { nal do MERCO- } \\
\text { SUL" (AMARAL } \\
\text { JR., 2008: 415) }\end{array}$ & $\begin{array}{l}\text { Parlamentares } \\
\text { representantes } \\
\text { dos Estados- } \\
\text {-partes }\end{array}$ & $\begin{array}{l}\text { Recomendações, não } \\
\text { obrigatórias, que são } \\
\text { enviadas ao CMC, por } \\
\text { meio do GMC }\end{array}$ \\
\hline
\end{tabular}




\begin{tabular}{|c|c|c|c|c|}
\hline $\begin{array}{l}\text { ARTIGOS - } \\
\text { PROT. OURO } \\
\text { PRETO }\end{array}$ & ÓRGÃO & $\begin{array}{c}\text { PRINCIPAL } \\
\text { FUNÇÃO OU } \\
\text { ATRIBUIÇÃO }\end{array}$ & $\begin{array}{c}\text { QUEM } \\
\text { PARTICIPA }\end{array}$ & $\begin{array}{c}\text { PRONUNCIAMENTO } \\
\text { OCORRE POR MEIO } \\
\text { DE... }\end{array}$ \\
\hline 28 a 30 & $\begin{array}{l}\text { Foro } \\
\text { Consultivo } \\
\text { Econômi- } \\
\text { co Social } \\
\text { (FCES) }\end{array}$ & $\begin{array}{l}\text { Órgão de repre- } \\
\text { sentação dos } \\
\text { setores econômi- } \\
\text { cos e sociais, de } \\
\text { função consultiva }\end{array}$ & $\begin{array}{l}\text { Representan- } \\
\text { tes de cada } \\
\text { Estado-parte }\end{array}$ & $\begin{array}{l}\text {-*- O órgão apenas } \\
\text { deve submeter seu } \\
\text { Regulamento Interno } \\
\text { ao GMC, para homo- } \\
\text { logação }\end{array}$ \\
\hline 31 a 33 & $\begin{array}{l}\text { Secretaria } \\
\text { Administra- } \\
\text { tiva }\end{array}$ & $\begin{array}{l}\text { Órgão de apoio } \\
\text { operacional, que } \\
\text { cuida do arquiva- } \\
\text { mento de instru- } \\
\text { mentos legais e } \\
\text { da organização } \\
\text { de reuniões, } \\
\text { publicações e di- } \\
\text { fusão das normas }\end{array}$ & $\begin{array}{l}\text { Diretor, eleito } \\
\text { de forma rota- } \\
\text { tiva pelo GMC } \\
\text { e designado } \\
\text { pelo CMC. } \\
\text { Mandato de } \\
\text { dois anos, } \\
\text { sendo proibida } \\
\text { a reeleição }\end{array}$ & n. a. \\
\hline
\end{tabular}

Fonte: elaboração própria, com base em: Protocolo Adicional ao Tratado de Asunción sobre la Estructura Institucional del MERCOSUR - Protocolo de Ouro Preto (1994); AMARAL JR. (2008, p. 408-416).

O Setor Educacional do MERCOSUL resulta da Decisão CMC n. 05/91, a qual cria as reuniões de ministros dos Estados-partes. Tal decisão foi referendada no Art. $8^{\circ}$ do Protocolo de Ouro Preto. Sua estrutura compreende a Reunião de Ministros de Educação (RME), o Comitê Coordenador Regional (CCR), um comitê gestor do Sistema de Informação e Comunicação (CGSIC), dois comitês assessores, um sobre políticas linguísticas (CAPL) e um voltado para o Fundo de Financiamento do Setor Educativo do MERCOSUL (CAFEM). Há quatro comissões regionais: a da Educação Básica (CRCEB), a de Coordenação de Educação Tecnológica (CRCET), a de Coordenação de Formação Docente (CRCFD) e a Comissão Regional Coordenadora de Educação Superior (CRCES), que será abordada em destaque a seguir (MERCOSUL EDUCACIONAL, 2013).

A instância máxima do Setor Educacional do MERCOSUL é a Reunião de Ministros da Educação (RME), a qual, constituída pelos Ministros de Educação dos Estados-partes, tem por função auxiliar com contribuições para que ocorra o desenvolvimento de políticas públicas no campo educacional que vão ao encontro dos objetivos de integração e desenvolvimentos dos membros do MERCOSUL. Embora não tenha capacidade decisória no âmbito do MERCOSUL, a Reunião de Ministros possui autonomia no que se refere ao desenvolvimento de planos relacionados especificamente ao setor educacional.

O Comitê Coordenador Regional (CCR), formado por representantes das Comissões Nacionais de Educação dos Estados-partes, exerce funções de assessoria ao RME e propõe as chamadas políticas de integração e cooperação, além de desenvolver os programas anuais de atividades e os planos de ação. 
As Comissões Regionais têm por função realizar a planificação e efetiva implementação das linhas de ação de cada nível a que estão destinadas. Também são responsáveis pela avaliação e pelo acompanhamento dos projetos desenvolvidos e são compostas por pessoas técnicas que atuam com Educação. Os Grupos de Trabalho, atualmente denominados Grupos Gestores de Projetos, são compostos por técnicos convocados ad hoc para desenvolverem projetos que foram aprovados pelo Setor Educacional do MERCOSUL.

Levando em conta o escopo deste trabalho, realizou-se uma análise do conteúdo dos documentos publicados na página do MERCOSUL e que estão diretamente relacionados à Educação Superior Universitária. Faz-se, quando necessário, um breve registro dos outros documentos que se referem à Educação, em níveis que não são objeto de estudo deste artigo, para que se possa compreender o conjunto de ações envolvendo o assunto e se há ações efetivas que vão ao encontro da visão da Educação Superior como de importância estratégica para o desenvolvimento dos países, porta de integração e de geração de riquezas (RAIZER, 2007; MARTINEZ, 2000; MOTA, 2000; SCHWARTZMAN, 2000). Um resumo dos documentos analisados encontra-se nos Apêndices.

Observa-se, pelos documentos analisados relativos à Educação Superior, que há diversas tentativas do MERCOSUL visando à maior integração dos países mediante acordos e protocolos que propõem o envolvimento de cada Estado-parte e dos Estados Associados em atividades relacionadas a intercâmbio e reconhecimento da qualidade dos cursos na área acadêmica. Nos níveis iniciais de educação e até o terciário técnico, constata-se que houve mais avanços do que no terciário universitário. É possível que os atores em campo, em especial a oligarquia acadêmica, apresente algumas resistências ao que se poderia, até, denominar de 'reserva de mercado'. A pesquisa realizada em 2013 e apresentada a seguir procurará trazer alguns elementos que visam identificar possíveis respostas sobre obstáculos e incentivos à integração por meio da Educação Superior.

Pode-se inferir que um dos acordos mais relevantes, em termos práticos, foi a criação do sistema ARCU-SUR. Em 2007, na XXII Reunião de Ministros da Educação dos quatro países que compõem os Estados-partes do MERCOSUL (Argentina, Brasil, Paraguai e Uruguai) e pelos países associados Bolívia e Chile, foi assinado o Memorandum de entendimento sobre la creación e implementación de un sistema de acreditación de carreras universitarias para el reconocimiento regional de la calidad académica de las respectivas titulaciones en el MERCOSUR e estados asociados. O memorando, como apresentado, tratou da criação e implementação do Sistema de Acreditación Regional de Carreras Universitarias del MERCOSUR, denominado ARCU-SUR, depois da experiência de avaliação experimental dos cursos de Agronomia, Engenharia e Medicina realizada pelo Mecanismo Experimental de Acreditación (MEXA) em 2006 (MERCOSUR, 2008).

O mecanismo de administração do sistema ARCU-SUR estabelece a organização das agências nacionais de acreditação como uma rede - a Red de Agencias Nacionales de Acreditación (RANA) e com decisão por consenso. Controvérsias serão resolvidas pelo sistema de controvérsias do MERCOSUL. Todavia, aspectos como diferentes configurações das agências reguladoras fogem do escopo do sistema de controvérsias e impactam o processo. Esse ponto está presente quando se constata que no Brasil tanto regulação quanto avaliação são da mesma competência da agência nacional, enquanto no Paraguai 
apenas a avaliação é papel da agência reguladora, sendo a regulação competência do Judiciário. Na Argentina, a CONEAU está sobrecarregada de tarefas e, no Uruguai, ainda não há, oficialmente, a agência de acreditação.

O que se destaca, portanto, é que, respeitando-se as legislações de cada país e os princípios de autonomia constantes em cada arcabouço legal, busca-se, por meio das agências nacionais de acreditação, aplicar a proposição de integração pela educação superior. A maior mobilidade de profissionais entre os Estados-parte e Associados do MERCOSUL é um dos objetivos de uma integração e dos princípios de troca de conhecimentos entre países que estão presentes nas leis aqui estudadas, mais explicitamente nos casos de Argentina, Paraguai e Uruguai.

Ao comparar a redação deste documento com a do Acordo de mesmo nome, assinado em 2008, identifica-se que quase todas as proposições foram aceitas, exceto a permissão ao exercício da atividade profissional nos outros países, ou seja, o efeito do credenciamento como o reconhecimento mútuo da qualidade acadêmica dos títulos ou diplomas que tiverem suas carreiras (cursos) reconhecidas pelo sistema ARCU-SUR foi mantido; contudo, o "senão" mais ousado - o exercício profissional em convênios, tratados ou acordos multilaterais, regionais ou até sub-regionais - perdeu o round, mas não a batalha.

Para finalizar esta parte, identifica-se que, no tocante à Educação Superior, até setembro de 2014, estão de fato vigentes, isto é, ratificados por Argentina, Brasil, Paraguai e Uruguai: o DOC. n. 19 - Protocolo de Integración Educativa para la Formación de Recursos Humanos a Nivel de Post-grado entre los Países Miembros del MERCOSUR. Firmado: Fortaleza, 16 dez. 1996. Dec. n. 09/96; o Doc. n. 21 - Protocolo de Integración Educativa para la Prosecución de Estudios de Post-grado en las Universidades de los Países Miembros del MERCOSUR. Firmado: Fortaleza, 16 dez. 1996. Dec. n. 08/96; e o Doc. n. 37 - Acuerdo de Admisión de Títulos y Grados Universitarios para el Ejercicio de Actividades Académicas en los Estados-parte del MERCOSUR. Firmado: Asunción, 14 jun. 1999. Dec. n. 04/99 (MERCOSUR, 2014, s/p.)

\section{PERCEPÇÕES SOBRE O MERCOSUL EDUCACIONAL}

Em complemento à análise acima, foi realizada uma pesquisa via internet, para identificar a percepção dos atores do campo educacional universitário (professores, estudantes, dirigentes e coordenadores de cursos, na graduação e pós-graduação de Universidades em Argentina, Brasil, Paraguai e Uruguai) quanto ao Setor Educacional do MERCOSUL. Partiu-se do pressuposto de que este setor, malgrado seus esforços de integração, ainda não se constitui em um marco para os países pesquisados, pouco impactando a condução de suas políticas no âmbito da Educação Superior Universitária.

A pesquisa consistiu de um questionário com 20 questões fechadas e duas questões abertas. Dividiu-se o conjunto pesquisado em dois grupos: grupo I (Argentina, Paraguai, Uruguai) e grupo II (Brasil), para verificar se havia diferenças de percepção entre os dois grupos. Foram enviados, para endereços eletrônicos de Universidades obtidos via web, carta de apresentação, seguindo-se as exigências éticas de pesquisa, e o link para o 
questionário, o qual ficou disponível na base google.docs, garantindo, assim, o anonimato do respondente. Endereços válidos: 2565, no Brasil e 454, em Argentina, Paraguai e Uruguai. De março a junho de 2013, período da pesquisa, houve 295 respostas, 45 do grupo I e 250 do grupo II, o que corresponde a $11,5 \%$ e $9,9 \%$ do total enviado a cada grupo, respectivamente.

A fim de avaliar a confiabilidade da escala, foi realizado um teste com o Alfa de Cronbach. Este método calcula o grau de semelhança ou homogeneidade de questões desenvolvidas em um questionário. Seu valor está contido em uma escala que varia de 0 a 1,0 , sendo que o valor mínimo necessário para que o tal coeficiente seja considerado adequado como índice de consistência interna depende do fenômeno estudado e do número de itens do questionário (BANDEIRA, 2013). O teste com o software Stata apresentou para a escala completa um Alfa de Cronbach de 0,9028, o que, de acordo com Freitas e Rodrigues (2005), é classificado no nível de confiabilidade muito alto.

\section{QUESTÕES OBJETIVAS}

Para as 20 questões objetivas, aplicou-se a Escala de Likert, com as opções: concordo totalmente (totalmente de acuerdo), mais concordo do que discordo (más en acuerdo que en desacuerdo), mais discordo do que concordo (más en desacuerdo que en acuerdo), discordo totalmente (totalmente en desacuerdo) e não sei responder (no lo sé). Comparando-se Argentina, Paraguai e Uruguai (Grupo I) com o Brasil (Grupo II), primeiramente encontra-se, na amostra, um nível de desconhecimento maior do Setor Educacional do MERCOSUL por parte dos respondentes do Brasil, em comparação com os respondentes de Argentina, Paraguai e Uruguai.

Nas respostas do grupo Argentina, Paraguai e Uruguai, há quatro questões (20\%) em que não houve desconhecimento algum. Nas outras, o maior porcentual de "no lo sé' está concentrado em 36\%, na questão 5 [Después del Mercosur Educativo hubo más solicitudes de homologación de estudios (reconocimiento de títulos) aprobadas en las instituciones de mi país]. A média de respostas com escolha à alternativa 'no lo sé é de 11\% no conjunto dos três países, contra $27 \%$ no caso dos respondentes brasileiros. As maiores diferenças em termos de índices de desconhecimento (acima de 20 pontos porcentuais) entre os grupos estão nas respostas do quadro 02.

Outro ponto de diferença que chama a atenção está em que os respondentes do Brasil, em geral, tendem a se posicionar menos favoravelmente no tocante ao reconhecimento do MERCOSUL como um marco na integração entre os países do que os respondentes de Argentina, Paraguai e Uruguai. Considerando-se a soma de respostas "concordo totalmente" e "mais de acordo do que em desacordo' nas questões cuja concordância indicam uma tendência de "favorabilidade", há, para o Brasil, um índice de "favorabilidade' de $37 \%$, contra $52 \%$ dos outros três países. 


\begin{tabular}{|l|c|c|c|}
\hline \multicolumn{1}{|c|}{ Afirmação } & $\begin{array}{c}\text { Nível de } \\
\text { desconhecimento } \\
\text { Argentina, } \\
\text { Paraguai e } \\
\text { Uruguai }\end{array}$ & $\begin{array}{c}\text { Nível de } \\
\text { desconhecimento } \\
\text { Brasil }\end{array}$ & $\begin{array}{c}\text { Diferença } \\
\text { (em pontos } \\
\text { porcentuais) }\end{array}$ \\
\hline $\begin{array}{l}\text { 1.1. O Mercosul Educacional é um } \\
\text { marco na integração dos países }\end{array}$ & $0 \%$ & $22 \%$ & 22 \\
\hline $\begin{array}{l}\text { 1.3. O Mercosul Educacional mu- } \\
\text { dou a estrutura das leis educacio- } \\
\text { nais no meu País }\end{array}$ & $12 \%$ & $33 \%$ & 21 \\
\hline $\begin{array}{l}\text { 1.6. Depois do Mercosul Educacio- } \\
\text { nal houve uma mudança nas deci- } \\
\text { sões judiciais sobre pedidos de re- } \\
\text { conhecimento de títulos de cursos } \\
\text { realizados fora do meu País }\end{array}$ & $31 \%$ & $55 \%$ & \\
\hline $\begin{array}{l}\text { 1.7. Depois do Mercosul Educacio- } \\
\text { nal houve um aumento nas aprova- } \\
\text { ções das decisões judiciais para pe- } \\
\text { didos de reconhecimento de cursos } \\
\text { realizados fora do meu País }\end{array}$ & $33 \%$ & $57 \%$ & 24 \\
\hline $\begin{array}{l}\text { 1.8. No meu País, o Mercosul Edu- } \\
\text { cacional cumpre os objetivos que } \\
\text { se propôs }\end{array}$ & & & \\
\hline $\begin{array}{l}\text { 1.16. A "acreditação" no Sistema } \\
\text { ARCU-SUR facilita o reconheci- } \\
\text { mento mútuo de títulos para o exer- } \\
\text { cício profissional em outros países }\end{array}$ & $10 \%$ & $39 \%$ & \\
\hline $\begin{array}{l}\text { 1.18. Os acordos de reconheci- } \\
\text { mento de títulos de cursos constan- } \\
\text { tes na estratégia do Mercosul estão } \\
\text { sendo efetivos na prática }\end{array}$ & $14 \%$ & \\
\hline
\end{tabular}

QUADRO 02

MAIORES DIFERENÇAS EM TERMOS DE ÍNDICES DE DESCONHECIMENTO ENTRE OS GRUPOS: (I) Argentina, Paraguai e Uruguai e (II) Brasil Fonte: elaboração própria.

Analisando-se as afirmações 9, 10, 13 e 19, cujas respostas "concordo totalmente" e "mais de acordo do que em desacordo" refletem posições desfavoráveis ao reconhecimento do MERCOSUL, os resultados demonstram que os respondentes do Brasil posicionam-se com menor intensidade em discordar das afirmações do que os respondentes de Argentina, Paraguai e Uruguai (53\% de "desfavorabilidade" contra 62\%). As maiores diferenças (mais de 20 pontos porcentuais) em termos de posição dos grupos com relação às afirmações são encontradas nas questões 1.1, 1.8, 1.9, 1.16 e 1.20, conforme quadro 03. 
Com relação às semelhanças, observa-se que o nível de desconhecimento é parecido apenas na questão 1.10 - Não há como homologar estudos cursados em outro país para poder trabalhar porque as universidades estrangeiras apresentam estruturas diferentes das nacionais, com uma diferença de $2 \%$ maior no caso brasileiro. Em todas as outras afirmações, o nível de resposta "não sei" é sempre maior no grupo brasileiro, indo de 4 a 37 pontos porcentuais, no caso da afirmação 1.8 - No meu País, o Mercosul Educacional cumpre os objetivos que se propôs. Essa é uma diferença que merece um olhar mais específico, pois, nas respostas abertas, novamente encontra-se, por parte dos respondentes brasileiros, comentários sobre a falta de informação acerca do que faz o Setor Educacional do MERCOSUL e até a reafirmação do total desconhecimento quanto à existência deste setor. Cabe ressaltar, ainda, que na amostra apresentam-se indícios de que no Brasil há mais resistência ao reconhecimento do Setor Educacional do MERCOSUL como um marco na integração entre os países, porém, é necessário realizar outros estudos para que possa ser evidenciada uma comprovação estatística desta percepção.

\begin{tabular}{|c|c|}
\hline AFIRMAÇÃO & POSIÇÕES DISTINTAS \\
\hline $\begin{array}{l}1.1 \text { O Mercosul Educacional é um } \\
\text { marco na integração dos países }\end{array}$ & $\begin{array}{l}\text { Enquanto apenas } \mathbf{2 7} \% \text { dos respondentes brasileiros } \\
\text { concordam totalmente com esta afirmação, } \mathbf{5 5 \%} \\
\text { dos respondentes de Argentina, Paraguai e Uruguai } \\
\text { elegem esta resposta }\end{array}$ \\
\hline $\begin{array}{l}1.8 \text { No meu País, o Mercosul Edu- } \\
\text { cacional cumpre os objetivos que se } \\
\text { propôs }\end{array}$ & $\begin{array}{l}\mathbf{1 5} \% \text { dos respondentes brasileiros mais concordam } \\
\text { do que discordam desta afirmação, contra } \mathbf{3 6} \% \text { dos } \\
\text { respondentes de Argentina, Paraguai e Uruguai }\end{array}$ \\
\hline $\begin{array}{l}1.9 \text { O reconhecimento de títulos de } \\
\text { cursos realizados fora do País deve } \\
\text { ser de responsabilidade das universi- } \\
\text { dades, não do Mercosul Educacional }\end{array}$ & $\begin{array}{l}\mathbf{4 1} \% \text { dos respondentes brasileiros concordam total- } \\
\text { mente com esta afirmação, contra } \mathbf{1 2} \% \text { dos respon- } \\
\text { dentes de Argentina, Paraguai e Uruguai }\end{array}$ \\
\hline $\begin{array}{l}1.16 \text { A "acreditação" no Sistema } \\
\text { ARCU-SUR facilita o reconhecimen- } \\
\text { to mútuo de títulos para o exercício } \\
\text { profissional em outros países }\end{array}$ & $\begin{array}{l}\mathbf{8} \% \text { dos respondentes brasileiros concordam total- } \\
\text { mente com esta afirmação, contra } \mathbf{3 1} \% \text { dos respon- } \\
\text { dentes de Argentina, Paraguai e Uruguai }\end{array}$ \\
\hline $\begin{array}{l}\text { 1.20 Os diferentes sistemas nacionais } \\
\text { de educação facilitam o reconheci- } \\
\text { mento de títulos universitários }\end{array}$ & $\begin{array}{l}\mathbf{1 0} \% \text { dos respondentes brasileiros mais concordam } \\
\text { do que discordam desta afirmação, contra } \mathbf{3 1} \% \text { dos } \\
\text { respondentes de Argentina, Paraguai e Uruguai }\end{array}$ \\
\hline
\end{tabular}

\section{QUADRO 03}

POSIÇÕES DISTINTAS MAIS EXPRESSIVAS ENTRE OS GRUPOS:

(I) Argentina, Paragual e Urugual e (II) Brasil Fonte: elaboração própria.

\section{QUESTÕES ABERTAS}

No que se refere à questão 2: em seu ponto de vista, qual é o maior desafio para a integração educativa dos países do MERCOSUL? os respondentes de Argentina, Paraguai e Uruguai apontaram: 
Em primeiro lugar, questões relativas à acreditação/reconhecimento de títulos. Em 40\% das respostas, encontram-se comentários desta natureza: necessidade de se ter um sistema de acreditação (credenciamento) sério, com padrões regionais, o reconhecimento de títulos de forma recíproca, a diminuição de assimetrias, a exigência de obrigatoriedade de avaliação dos cursos e a consolidação do sistema ARCU-SUR. Em segundo lugar, em matéria de incidência de comentários, apresentam-se, em 28\% das respostas, considerações acerca dos distintos sistemas e estruturas como um obstáculo à integração entre os países no setor educacional. Em seguida, aparecem os obstáculos relativos a questões políticas e sistemas de poder, como interesses corporativos dos atores do meio educacional bloqueando a integração. Foram $21 \%$ do total com menção a este quesito. Por fim, 11\% das respostas mencionam questões legais.

No grupo do Brasil, houve poucas diferenças em termos porcentuais: 30\% apontam como maior desafio a acreditação; 30\%, questões políticas, culturais, interesses corporativos e questões de poder; $27 \%$ apontam as diferentes estruturas como desafio; $8 \%$, questões legais e 5\% não souberam responder. Registre-se, entretanto, comentários acerca de preconceito por parte do Brasil no tocante à qualidade dos cursos realizados nos outros países estudados - há menções quanto ao Brasil considerar-se superior, sem o ser, na visão dos respondentes ou, ainda, ser superior, sim e, portanto, não ser possível a integração sem haver uma melhoria na qualidade por parte dos outros países. Outro ponto que novamente vale lembrar é o maior desconhecimento, por parte dos respondentes brasileiros, no que se refere ao tema Setor Educacional do MERCOSUL.

No tocante à pergunta 3: que medidas o Mercosul Educacional deve tomar para possibilitar a real integração entre os países?, que é complemento da resposta anterior, os participantes de Argentina, Paraguai e Uruguai consideraram como importante: fortalecer as agências de acreditação e fomentar sua associação e interação entre países (maior índice de respostas, correspondendo a 37\% do total); em segundo lugar, em matéria de incidência, empatam, com $25 \%$ do total, a necessidade de gerar normativas comuns, com força de lei (o que vai ao encontro das respostas à questão 2, visto que os respondentes consideram a questão dos diferentes sistemas como impactante) e a necessidade de investir em comunicação para melhor difundir o que faz o Setor Educacional do MERCOSUL. Por fim, 13\% dos respondentes observaram a necessidade de favorecer o estabelecimento de conteúdos comuns, na linha do Tratado de Bolonha.

No caso dos respondentes brasileiros (grupo II), identifica-se uma fala pouco diferente da encontrada no grupo I: 37\% entendem que é preciso desenvolver mais ações de interação/intercâmbio, fazer cumprir os tratados, dar mais autonomia das Universidades/comunidade acadêmica, seja em expressões como deixar a universidade gerir o reconhecimento de títulos/mediação do reconhecimento de títulos, seja pela sensibilização dos atores, levando-se à inferência de que o Setor Educacional do MERCOSUL é pouco conhecido, talvez, pela junção de, na visão dos respondentes, uma atuação política acima da desejada e uma falta de informação, de compartilhamento, com os atores da área acadêmica; $25 \%$ propõem desenvolver grades e programas comuns e melhorar a informação; 22\% defendem o desenvolvimento de sistema de acreditação regional, acordos para reconhecimento automático de títulos e equalização de processos; $16 \%$ não sabem. 
A pesquisa realizada permite identificar que o grupo de respondentes do Brasil demonstra um nível de desconhecimento maior do que o grupo de respondentes de Argentina, Paraguai e Uruguai quanto ao Setor Educacional do MERCOSUL, bem como também demonstra menor aderência ao que foi denominado "favorabilidade" a reconhecer a efetividade desse setor no que concerne à integração entre países por meio da Educação Superior Universitária. Entretanto, como apontado, torna-se necessário realizar outros estudos, a fim de haver comprovação estatística desta percepção.

Outro ponto a ser destacado está na diferença de discurso encontrada nos dois grupos, estando o grupo do Brasil com mais índices de respostas relacionadas a questões culturais do que os encontrados em Argentina, Paraguai e Uruguai. Também se encontram no discurso do grupo brasileiro comparações de qualidade, em geral, colocando-se o Brasil acima dos demais países. No grupo brasileiro, encontram-se verbalizadas respostas contrárias à integração, denotando, na amostra pesquisada, mais falas preconceituosas do que se observa no discurso do grupo I - Argentina, Paraguai e Uruguai.

O desejo de haver maior integração e envolvimento da comunidade acadêmica aparece nos dois grupos, sendo um dos itens que o grupo de respondentes do Brasil mais salientou, inclusive apontando, de forma mais veemente, a necessidade de haver maior autonomia e participação da comunidade acadêmica nas políticas do Setor Educacional do MERCOSUL, visando a uma maior integração entre os países.

Pode-se concluir que, na amostra estudada, os respondentes identificam aspectos estruturais, culturais e os interesses dos atores em campo educacional dos quatro países formadores constituintes do MERCOSUL como pontos mais considerados como empecilhos do que como alavancas à integração. Ademais, os respondentes não demonstram identificar o impacto do Setor Educacional do MERCOSUL em ações como reconhecimento de títulos ou mudanças nas formas das leis, corroborando o pressuposto ou hipótese inicial, embora os respondentes do grupo I - Argentina, Paraguai e Uruguai tenha apresentado diferença significativa em prol do reconhecimento do MERCOSUL como um órgão que cumpre o que se propôs, se comparada com as respostas do grupo II - Brasil.

\section{CONSIDERAÇÕES FINAIS}

Observa-se, pelos documentos analisados relativos à Educação Superior, que há diversas tentativas do MERCOSUL visando à maior integração dos países mediante acordos e protocolos que propõem o envolvimento de cada Estado-parte e dos Estados Associados em atividades relacionadas a intercâmbio e reconhecimento de títulos na área acadêmica. Nos níveis iniciais de educação e até o terciário técnico, constata-se que houve mais avanços nos estratos anteriores do que no terciário universitário, no tocante à efetivação das propostas e recomendações do SEM.

O exercício profissional tem se mostrado, até o momento, o ponto de maior divergência no tocante aos acordos de reconhecimento de títulos em nível universitário e aqui aparecem as expressões coletadas na pesquisa realizada e em 2013: "reserva de mercado", "interesses políticos", "associações de classe" como empecilhos à integração. 
Provavelmente, a maior lentidão vista nos avanços no campo universitário possa ser decorrente da luta dos diversos atores em campo, como as associações profissionais, as oligarquias acadêmicas, os políticos e seus distintos interesses.

Um marco que não pode deixar de ser registrado como favorável à integração, por se tratar de um dos acordos mais relevantes, em termos práticos, foi a criação do sistema ARCU-SUR, que estabelece a organização das agências nacionais de acreditação $^{(1)}$ como uma rede - a Red de Agencias Nacionales de Acreditación (RANA). Mais recentemente, o sistema integrado de mobilidade do MERCOSUL - SIMERCOSUL também merece destaque, como uma proposta de consolidação de um sistema de mobilidade em educação incorporando os programas existentes de mobilidade acadêmica universitária do Setor Educacional do MERCOSUL (SEM), como o MARCA.

A pesquisa realizada permite identificar que o grupo de respondentes do Brasil demonstra um nível de desconhecimento maior do que o grupo de respondentes de Argentina, Paraguai e Uruguai quanto ao Setor Educacional do MERCOSUL (SEM), bem como também mostra menor aderência ao que foi denominado "favorabilidade" a reconhecer a efetividade desse setor no que concerne à integração entre países por meio da Educação Superior Universitária. Entretanto, como apontado, torna-se necessário realizar outros estudos, a fim de haver comprovação estatística desta percepção.

Outro ponto a ser destacado está na diferença de discurso encontrada nos dois grupos, estando o grupo do Brasil com mais índices de respostas relacionadas a questões culturais do que os encontrados em Argentina, Paraguai e Uruguai. Também se depararam no discurso do grupo brasileiro comparações de qualidade, em geral, colocando-se o Brasil acima dos demais países. No grupo brasileiro, encontram-se verbalizadas respostas contrárias à integração, denotando, na amostra pesquisada, mais falas preconceituosas ou críticas do que se observa no discurso do grupo I - Argentina, Paraguai e Uruguai.

O desejo de haver maior integração e envolvimento da comunidade acadêmica aparece nos dois grupos, sendo um dos itens que o grupo de respondentes do Brasil mais salientou, inclusive apontando, de forma mais veemente, a necessidade de haver maior autonomia e participação da comunidade acadêmica nas políticas do Setor Educacional do MERCOSUL, visando a uma maior integração entre os países.

Pode-se concluir que, na amostra estudada, os respondentes identificam aspectos estruturais, culturais e os interesses dos atores em campo educacional dos quatro países formadores constituintes do MERCOSUL como pontos mais considerados como empecilhos do que como alavancas à integração. Ademais, os respondentes não demonstram identificar o impacto do Setor Educacional do MERCOSUL em ações como reconhecimento de títulos ou mudanças nas formas das leis, ou seja, não se consegue identificar, no conjunto estudado, uma percepção de impacto do SEM no que se refere à condução de suas políticas no âmbito da Educação Superior Universitária, corroborando o pres-

(1) O sistema ARCU-SUL visa avaliar e realizar a acreditação de cursos no nível universitário, isto é, ele é como um selo de garantia pública do nível acadêmico e científico de cada curso universitário que faz parte por ingresso voluntário. Fazem parte, atualmente, cursos de Agronomia, Arquitetura, Enfermagem, Engenharia, Medicina, Odontologia e Veterinária - vide detalhes na Decisão CMC n. 17/08 (BRASIL, Ministério da Educação, 2014). 
suposto ou hipótese inicial, embora os respondentes do grupo I - Argentina, Paraguai e Uruguai tenha apresentado diferença significativa em prol do reconhecimento do MERCOSUL como um órgão que cumpre o que se propôs, se comparada com as respostas do grupo II - Brasil.

No entanto, reforça-se, é patente a necessidade de haver mais estudos, abrangendo distintos atores no âmbito universitário, para ampliar o conhecimento sobre o tema e corroborar - ou não - o resultado encontrado nesta pesquisa, sendo que um possível ponto de aprofundamento pode estar no estudo da burocracia de médio escalão e de sua ação que pode ser favorável ou desfavorável à implantação efetiva das proposições emitidas pelo SEM.

\section{BIBLIOGRAFIA}

\subsection{LIVROS E ARTIGOS}

ALMEIDA, Elizabeth Accioly Pinto. MERCOSUL E União Europeia. Estrutura Jurídico-institucional. Curitiba: Juruá, 1996.

AMARAL JUNIOR, Alberto do. Introdução ao Direito Internacional Público. São Paulo: Atlas, 2008. CELLIJUNIOR, Umberto. Teoria Geral da integração: em busca de um modelo alternativo. In: MERCADANTE, Araminta de Azevedo; CELLIJUNIOR, Umberto; ARAÚJO, Leandro Rocha de (org.) Blocos Econômicos e Integração na América Latina, África e Ásia. Curitiba: Juruá, 2006.

COSTA, Márcia Caetano. O MERCOSUL e as universidades: ¿integración? Passo Fundo: UPF, 2003.

DEVLIN, Robert; ESTEVADEORDAL, Antoni. What's new in the new regionalism in the Américas? In: Intal-ITD-STA, Working Paper n. 06, ma, 2001.

FREITAS, André Luís Policani; RODRIGUES, Sidilene Gonçalves. A avaliação da confiabilidade de questionários: uma análise utilizando o coeficiente alfa de Cronbach. In: XII SIMPEP. Bauru, Brasil, 2005.

GONÇALVES, Paulo Sergio. A pós-graduação no Brasil em termos do acordo de admissão de títulos e graus universitários para o exercício de atividades acadêmicas nos estados partes do MERCOSUL. 2012. 86 p. (Dissertação em Educação), Programa de pós-graduação em Educação, Universidade Estadual do Maringá, Maringá.

MARTINEZ, Paulo Henrique. Papel estratégico dos estudos latino-americanos. In: CATANI, Afrânio Mendes. (Org.) América Latina: impasses e alternativas. São Paulo: Edusp, 2000.

MENEZES, Wagner. Mercado Comum do Sul (MERCOSUL). In: MERCADANTE, Araminta de Azevedo; CELLI JUNIOR, Umberto; ARAÚJO, Leandro Rocha de (org.) Blocos Econômicos e Integração na América Latina, África e Ásia. Curitiba: Juruá, 2006. pp. 137-159.

MOTA, Carlos Guilherme. Uma universidade para o MERCOSUL. In: CATANI, Afrânio Mendes. (Org.) América Latina: impasses e alternativas. São Paulo: Edusp, 2000.

PEÑA, Félix. La integración del espacio sudamericano. ¿La Unasur y el Mercosur pueden complementarse? In: Nueva Sociedad, n. 219, enero-febrero 2009.

RAIZER, Leandro. Educação para a Integração: Rumo ao Setor Educacional do MERCOSUL? In: Políticas Educativas. Montevideo, v. 1, n. 1, pp. 156-169, 2007.

SCHWARTZMAN, Simon. A Revolução Silenciosa no Ensino Superior. In: DURHAM, Eunice Ribeiro; SAMPAIO, Helena. O Ensino Superior em Transformação. São Paulo, Núcleo de Pesquisas sobre Ensino Superior (NUPES/USP), 2000, p. 13-30. 


\subsection{DOCUMENTOS E WEB SITES}

BANDEIRA, Marina. Texto 9. Definição das variáveis e métodos de coleta dedados. [on-line], 2013. Disponível em: <http://www.ufsj.edu.br/portal-repositorio/File/lapsam/Texto\%209-DEFINICAO\%20 E\%20COLETA.pdf> Acesso em: 19 jul. 2013.

MERCOSUR. Estado de ratificaciones y vigencias de tratados y protocolos del mercosur y estados asociados. 2014. Disponível em: <www.mercosur.int> Acesso em: 25 set. 2014.

MERCOSUL. Protocolo Adicional ao Tratado de Asunción sobre la Estructura Institucional del Mercosur -Protocolo de Ouro Preto. 1994. Disponível em:<http://www.mercosur.int> Acesso em: 16 jul. 2013.

MERCOSUl EDUCACIONAL. Instâncias do Setor Educacional do Mercosul. 2013. Disponível em: <http://www.sic.inep.gov.br/pt-BR/MERCOSUL-educacional/instancias.html> Acesso em: 17 jul. 2013

MERCOSUR EDUCATIVO. Sistema de acreditación de carreras universitarias para el reconocimiento regional de la calidad académica de sus respectivas titulaciones en el MERCOSURy Estados Asociados. 2008.

Disponível em: <http://www.coneau.gov.ar/archivos/files/MANUALSISTEMAARCUSUR_version12_08.pdf.> Acesso em: 17 jul. 2013.

\section{APÊNDICES - DOCUMENTOS ANALISADOS PUBLICADOS NA PÁGINA DO MERCOSUL}

(fonte: <http://www.mercosur.int/>)

Legenda:

DOCUMENTO $=$ DEC $=$ Decisão

DOCUMENTO = RES = Resolução

De 1991 a 1995

Continua

\begin{tabular}{|c|c|}
\hline Documento & Abrangência \\
\hline $\begin{array}{l}\text { MERCOSUL/ } \\
\text { CMC/DEC n. } \\
5 / 91\end{array}$ & $\begin{array}{l}\text { Cria a reunião de ministros, dado que a constituição do MERCOSUL exige o } \\
\text { tratamento de assuntos de diversas competências, para os quais é necessário } \\
\text { o envolvimento das hierarquias mais altas ministeriais de cada Estado. }\end{array}$ \\
\hline $\begin{array}{l}\text { MERCOSUL/ } \\
\text { CMC/DEC n. } \\
7 / 91\end{array}$ & $\begin{array}{l}\text { Registra a primeira reunião de ministros da Educação dos Estados-partes, e } \\
\text { o CMC, considerando que "[...] a formação integral dos recursos humanos } \\
\text { mediante a elevação dos níveis de educação é fator essencial para fortalecer o } \\
\text { processo de integração" (MERCOSUL/CMC/DEC n. 7/91, 1991, s/p.), decide } \\
\text { criar a reunião de Ministros da Educação, com a função de propor medidas } \\
\text { para coordenar as políticas educacionais de cada Estado-parte (BRASIL, 2013). }\end{array}$ \\
\hline $\begin{array}{l}\text { MERCOSUL/ } \\
\text { CMC/DEC. n. } \\
07 / 92\end{array}$ & $\begin{array}{l}\text { Aprova o "Plano Trienal para o Setor Educação no Contexto do MERCO- } \\
\text { SUL", considerando a questão da formação de uma consciência cidadã que } \\
\text { seja favorável ao processo de integração, bem como a necessidade de ca- } \\
\text { pacitar pessoas, conciliar e harmonizar os sistemas educacionais de cada } \\
\text { Estado-parte como sustentação para a conformação do MERCOSUL. }\end{array}$ \\
\hline $\begin{array}{l}\text { MERCOSUL/ } \\
\text { CMC/DEC. } \\
\text { n. } 4 / 94\end{array}$ & $\begin{array}{l}\text { Registra a aprovação do "Protocolo de Integração Educativa e de Reconhecimen- } \\
\text { to de Certificados, Títulos e Estudos de Nível Primário e Nível Médio Não Técni- } \\
\text { co", levando em conta o "Art. } 10 \text { do Tratado de Assunção, as Decisões ns. 4/91, } \\
\text { 5/91 e 7/91 do Conselho do Mercado Comum e a Resolução n. 39/94 do Grupo } \\
\text { Mercado Comum" (MERCOSUL/CMC/DEC n. 4/94, 1994:1, in Brasil, 2013). }\end{array}$ \\
\hline
\end{tabular}




\begin{tabular}{|l|l|}
\hline Documento & Abrangência \\
\hline MERCOSUL/ & Mantém a reuniããa de ministros da Educação dentre o rol de assuntos que \\
CMC/DEC. & devem ser tratados de forma específica. No mesmo ano, apresenta-se a pri- \\
n. 1/95 & $\begin{array}{l}\text { meira tentativa de aprovar um protocolo de integração educativa sobre re- } \\
\text { conhecimento de títulos universitários para o prosseguimento de estudos de } \\
\text { pós-graduação nas universidades dos países do MERCOSUL; no entanto, } \\
\text { essa decisão foi derrogada pela 08/96. }\end{array}$ \\
\hline
\end{tabular}

MERCOSUL/CMC/DEC. n. 7/95

Aprova o "Protocolo de Integração Educativa e Revalidação de Diplomas, Certificados, Títulos e Reconhecimento de Estudos de Nível Médio Técnico" no que diz respeito à sua validade acadêmica, de acordo com o "Tratado de Assunção e seus Protocolos Adicionais, as Decisões ns. 4/91, 5/91 e 7/91 do Conselho do Mercado Comum e a Resolução n. 18/95 do Grupo Mercado Comum" (MERCOSUL/CMC/DEC. n. 7/95, 1995: 1, in Brasil, 2013).

MERCOSUL/ CMC aprova o PROGRAMA DE AÇÃO DO MERCOSUL até o ano 2000. CMC/DEC. Para a educação, ressalta-se a importância de aprofundar a integração n. 9/95 educativa, articular os sistemas de informação nacionais e reconhecer a formação acadêmica (MERCOSUL/CMC/DEC. n. 9/95, 1995:12, in Brasil, 2013).

De 1996 a 2000

Continua

\begin{tabular}{|l|l|}
\hline \multicolumn{1}{|c|}{ Documento } & Abrangência \\
\hline MERCOSUL/ & É o primeiro documento aprovado e vigente, no tocante à educação superior \\
n. 8/96 & $\begin{array}{l}\text { universitária. Esta decisão trata da aprovação, pelo CMC, do "Protocolo de } \\
\text { integração educacional para prosseguimento de estudos de pós-graduação } \\
\text { nas universidades dos estados partes do MERCOSUL. O art. 1o determina } \\
\text { que o reconhecimento de títulos universitários deve ser feito "unicamente } \\
\text { para a realização de estudos de pós-graduação acadêmica" (MERCOSUL/ } \\
\text { CMC/DEC. n. 8/96, 1986, p. 2). O art. 40 ressalta que o reconhecimento do } \\
\text { diploma não habilita ao exercício da profissão. Este protocolo está vigente } \\
\text { em Argentina, Brasil, Paraguai e Uruguai. Cabe ressaltar que foi ratificada } \\
\text { em 1997 no Paraguai, em 1999 em Argentina e Brasil e apenas em 2000 } \\
\text { no Uruguai. No Uruguai, talvez a forte oligarquia acadêmica (lembrar que } \\
\text { a Universidad de la República é parte integrante do processo de análise e } \\
\text { aprovação de medidas mercosulinas) tenha impacto, mais do que no Para- } \\
\text { guai, país também de tradição oligárquica forte no que concerne à acade- } \\
\text { mia. }\end{array}$ \\
\hline $\begin{array}{l}\text { MERCOSUL/ } \\
\text { CMC/DEC. } \\
\text { n. 9/96 }\end{array}$ & $\begin{array}{l}\text { como fundamental no chamado processo de integração regional e na mo- } \\
\text { dernização dos Estados-partes. Recordando o compromisso assumido no } \\
\text { Plano Trienal para a Educação, Programas I.3 e II.4, o CMC aprova o "Pro- } \\
\text { tocolo de integração educacional para a formação de recursos humanos no } \\
\text { nível de pós-graduação entre os estados-partes do MERCOSUL. Este pro- } \\
\text { tocolo está vigente nos quatro Estados-partes originários do MERCOSUL } \\
\text { (Argentina, Brasil, Paraguai e Uruguai). }\end{array}$ \\
\hline
\end{tabular}




\begin{tabular}{|c|c|}
\hline Documento & Abrangência \\
\hline $\begin{array}{l}\text { MERCOSUL/ } \\
\text { CMC/DEC. } \\
\text { n. } 11 / 96\end{array}$ & $\begin{array}{l}\text { Trata do protocolo de integração cultural do MERCOSUL e merece registro } \\
\text { porque envolve a participação de pesquisadores que possam fortalecer o } \\
\text { intercâmbio cultural, sendo que a compreensão da cultura do 'outro' pode } \\
\text { abrir caminho para a integração. }\end{array}$ \\
\hline $\begin{array}{l}\text { MERCOSUL/ } \\
\text { CMC/DEC n. } \\
3 / 97\end{array}$ & $\begin{array}{l}\text { Trata-se da segunda decisão no âmbito da Educação Superior Universitária } \\
\text { que foi derrogada, agora pela Decisão CMC 04/99. Trata-se da MERCOSUL/ } \\
\text { CMC/DEC n. 3/97, que aprovava o "Protocolo de admissão de títulos e graus } \\
\text { universitários para o exercício de atividades acadêmicas nos estados-partes } \\
\text { do MERCOSUL". }\end{array}$ \\
\hline $\begin{array}{l}\text { MERCOSUL/ } \\
\text { CMC/DEC n. } \\
26 / 97\end{array}$ & $\begin{array}{l}\text { Apresenta o anexo ao protocolo acima referido, e também foi derrogada } \\
\text { pela Decisão CMC 04/99. Esta, por sua vez, ainda está pendente de ratifica- } \\
\text { ção no Uruguai e foi ratificada pelos outros países nos seguintes momentos: } \\
\text { na Argentina, em 2002; no Brasil, em 2004; no Paraguai, somente em } 2010 . \\
\text { Pode-se considerar possíveis resistências quanto ao impacto das oligarquias } \\
\text { acadêmicas, que são bastante fortes em Paraguai e Uruguai, como também } \\
\text { se pode remontar a questões de mercado, ou econômicas, que levem a uma } \\
\text { resistência em aprovar esta decisão. O Paraguai tem demonstrado frequente } \\
\text { êxodo de jovens para outros países, o que pode ser um fator que também } \\
\text { crie resistência, ainda que se esteja abordando o exercício de atividades } \\
\text { acadêmicas. }\end{array}$ \\
\hline $\begin{array}{l}\text { MERCOSUL/ } \\
\text { CMC/DEC n. } \\
22 / 97\end{array}$ & $\begin{array}{l}\text { Trata do Protocolo de intenções entre o Mercado Comum do Sul (MER- } \\
\text { COSUL) e a Organização das Nações Unidas para a Educação, a Ciên- } \\
\text { cia e a Cultura (UNESCO), no qual a UNESCO poderá, por solicitação do } \\
\text { MERCOSUL, dar assistência na formulação e implementação de projetos de } \\
\text { cooperação, bem como buscar financiamento para execução de projetos e } \\
\text { programas na área da Educação e contratar estudos e pesquisas visando à } \\
\text { integração regional (Brasil, 2013). }\end{array}$ \\
\hline $\begin{array}{l}\text { MERCOSUL/ } \\
\text { CMC/DEC n. } \\
25 / 97\end{array}$ & Adia a vigência do plano trienal para a Educação até 30 de junho de 1998. \\
\hline $\begin{array}{l}\text { MERCOSUL/ } \\
\text { CMC/DEC n. } \\
13 / 98\end{array}$ & $\begin{array}{l}\text { Aprova o Plano Trienal de Educação e as metas para o setor educacional, } \\
\text { remontando a questões culturais históricas e valores comuns, respeitando-se } \\
\text { as singularidades da construção de cada país. Encontra-se como uma das } \\
\text { metas a implantação de agências de acreditação em cada país e a proposta } \\
\text { de criação de agências de acreditação nacionais, para cumprir os objetivos } \\
\text { do "Memorando de Entendimento sobre a Implementação de um Mecanis- } \\
\text { mo Experimental de Credenciamento de Cursos para o Reconhecimento de } \\
\text { Títulos de Graduação Universitária nos Países do MERCOSUL" (MERCO- } \\
\text { SUL/CMC/DEC n. 13/98, 1998:10, in Brasil, 2013), MEXA. }\end{array}$ \\
\hline $\begin{array}{l}\text { MERCOSUL/ } \\
\text { CMC/DEC. } \\
\text { n. } 4 / 99\end{array}$ & $\begin{array}{l}\text { Aprova o "Acordo de admissão de títulos e graus universitários para o exer- } \\
\text { cício de atividades acadêmicas nos estados partes do MERCOSUL". Houve } \\
\text { uma mudança na redação do proposto em 1997. Resumidamente: o que era } \\
\text { 'protocolo', transformou-se em 'acordo'; o texto ficou mais explícito com } \\
\text { relação ao objeto de intercâmbio, bem como às atividades abrangidas e no } \\
\text { tocante à necessidade de haver padrões de qualidade e de ter validação pela }\end{array}$ \\
\hline
\end{tabular}




\begin{tabular}{|l|l|}
\hline Documento & Abrangência \\
\hline & $\begin{array}{l}\text { legislação vigente em cada país. Fica patente, também, a preocupação com } \\
\text { a compreensão das diferenças. }\end{array}$ \\
\hline MERCOSUL/ & Denominada "Acordo de admissão de títulos e graus universitários para o \\
CMC/DEC. & $\begin{array}{l}\text { exercício de atividades acadêmicas nos estados-partes do MERCOSUL, na } \\
\text { República da Bolívia e na República do Chile" é a mesma decisão que a } \\
\text { 4/99, apenas extensiva, como o próprio título aponta, à Bolívia e ao Chile. } \\
\text { Até set. 2014, esta decisão somente foi ratificada, em junho, no Paraguai. }\end{array}$ \\
\hline
\end{tabular}

De 2001 a 2005

\begin{tabular}{|c|c|}
\hline Documento & Abrangência \\
\hline $\begin{array}{l}\text { MERCOSUL/ } \\
\text { CMC/DEC. n. } \\
\text { 15/01 }\end{array}$ & $\begin{array}{l}\text { Aprova a "Estrutura orgânica e Plano de Ação } 2001 \text { - } 2005 \text { do Setor Educa- } \\
\text { tivo do MERCOSUL, BOLÍVIA e CHILE. }\end{array}$ \\
\hline $\begin{array}{l}\text { MERCOSUL/ } \\
\text { CMC/DEC. n. } \\
\text { 26/02 }\end{array}$ & $\begin{array}{l}\text { Aprova o Protocolo de Integração Educativa e Reconhecimento de Certifi- } \\
\text { cados, Títulos e Estudos de Nível Fundamental e Médio Não Técnico, bem } \\
\text { como a Integração Educativa para a Formação de Recursos Humanos no } \\
\text { nível de pós-graduação e para o Prosseguimento de Estudos de Pós-gradua- } \\
\text { ção entre os Estados-partes do MERCOSUL, a República da BOLÍVIA e a } \\
\text { República do CHILE, mas esta decisão não está vigente. } \\
\text {... Continua }\end{array}$ \\
\hline $\begin{array}{l}\text { MERCOSUL/ } \\
\text { CMC/DEC. n. } \\
\text { 09/05 }\end{array}$ & $\begin{array}{l}\text {... Continuação. } \\
\text { Aprova o "acordo de admissão de títulos, certificados e diplomas para o } \\
\text { exercício da docência no ensino do espanhol e do português como línguas } \\
\text { estrangeiras nos Estados-partes", mas ele não está vigente, faltando a ratifi- } \\
\text { cação de Argentina e Brasil (BRASIL, 2013). }\end{array}$ \\
\hline
\end{tabular}

De 2006 a 2013

\begin{tabular}{|l|l|}
\hline Documento & Abrangência \\
\hline MERCOSUL/ & Aprova uma modificação na estrutura orgânica do setor educativo do MER- \\
CMC/DEC. n. & COSUL (SEM), e vem em complemento da decisão CMC No 15/01. Cria \\
05/06 & $\begin{array}{l}\text { O Comitê Assessor do Fundo do Setor Educativo do MERCOSUL (CAFEM) } \\
\text { para assessorar nas questões relacionadas ao Fundo do Setor Educativo do } \\
\text { MERCOSUR (FEM). }\end{array}$ \\
\hline $\begin{array}{l}\text { MERCOSUL/ } \\
\text { CMC/DEC. n. } \\
\text { 06/06 }\end{array}$ & $\begin{array}{l}\text { Cria o mecanismo para a implementação do protocolo de integração edu- } \\
\text { cativa e reconhecimento de certificados, títulos e estudos de nível primário } \\
\text { e médio não técnico. }\end{array}$ \\
\hline $\begin{array}{l}\text { CMC/DEC. n. } \\
\text { 21/06 }\end{array}$ & $\begin{array}{l}\text { Trata de acordo sobre gratuidade de vistos para estudantes e docentes dos } \\
\text { estados-partes do MERCOSUL que queiram solicitar visto de residência } \\
\text { para estudos, atividades de docência ou pesquisa. Ainda não vigente, pois } \\
\text { a Argentina não a ratificou. }\end{array}$ \\
\hline $\begin{array}{l}\text { MERCOSUL/ } \\
\text { CMC/DEC. n. } \\
\text { 04/07 }\end{array}$ & $\begin{array}{l}\text { Cria o Instituto MERCOSUL de Formação (IMEF), que visa capacitar funcio- } \\
\text { nários da Administração Pública na temática da integração regional. }\end{array}$ \\
\hline
\end{tabular}




\begin{tabular}{|c|c|}
\hline Documento & Abrangência \\
\hline $\begin{array}{l}\text { MERCOSUL/ } \\
\text { CMC/DEC. n. } \\
29 / 07\end{array}$ & $\begin{array}{l}\text { É referente ao acordo complementar de cooperação entre os Estados-partes } \\
\text { do Mercado Comum do Sul (MERCOSUL) e o convênio Andrés Bello (CAB) } \\
\text { sobre reconhecimento de estudos, títulos e certificados de educação pri- } \\
\text { mária/básica e média/secundária não técnica. Tal decisão não está vigente, } \\
\text { faltando as ratificações de todos os Estados-partes do MERCOSUL. }\end{array}$ \\
\hline $\begin{array}{l}\text { MERCOSUL/ } \\
\text { CMC/DEC. n. } \\
16 / 08\end{array}$ & $\begin{array}{l}\text { Trata da assinatura do protocolo de intenções entre o MERCOSUR e a Or- } \\
\text { ganização de Estados lbero-americanos para a Educação, a Ciência e a Cul- } \\
\text { tura, visando, em essência, desenvolver atividades de apoio aos programas } \\
\text { desenvolvidos pelas duas organizações. Este protocolo entrou em vigor na } \\
\text { data de sua assinatura, 30.6.2008. }\end{array}$ \\
\hline $\begin{array}{l}\text { MERCOSUL/ } \\
\text { CMC/DEC. n. } \\
17 / 08\end{array}$ & $\begin{array}{l}\text { Referente à criação do Sistema de Credenciamento Regional de Cursos } \\
\text { de Graduação dos Estados-partes do MERCOSUL e Estados Associados - } \\
\text { MEXA. Detalhes analisados no corpo deste trabalho. }\end{array}$ \\
\hline $\begin{array}{l}\text { MERCOSUL/ } \\
\text { CMC/DEC. n. } \\
20 / 08\end{array}$ & $\begin{array}{l}\text { Trata da adesão da República do Equador ao protocolo de integração edu- } \\
\text { cativa e reconhecimento de certificados, títulos e estudos de nível funda- } \\
\text { mental e médio não técnico entre os Estados-partes do MERCOSUL, a Re- } \\
\text { pública da Bolívia e a República do Chile. }\end{array}$ \\
\hline $\begin{array}{l}\text { MERCOSUL/ } \\
\text { CMC/DEC. n. } \\
24 / 08\end{array}$ & $\begin{array}{l}\text { Altera o texto publicado na Decisão CM } \\
\text { Financiamento do Setor Educacional do } \\
\text { participação dos Estados Associados. }\end{array}$ \\
\hline $\begin{array}{l}\text { R e s ol u çã o } \\
\text { MERCOSUL/ } \\
\text { GMC/RES. } \\
\text { n. } 63 / 08\end{array}$ & $\begin{array}{l}\text { Apresenta-se a primeira resolução relacionada à Educação Superior, que é } \\
\text { a, a qual aprova o acordo para o projeto denominado "Apoio ao Programa } \\
\text { de Mobilidade MERCOSUL em Educação Superior". Tal acordo tem o obje- } \\
\text { tivo de apoiar a condução da UdelaR em atividades relacionadas à pesquisa } \\
\text { de ações de mobilidade estudantil como a que ocorre com a Comunidade } \\
\text { Europeia. }\end{array}$ \\
\hline $\begin{array}{l}\text { MERCOSUL/ } \\
\text { CMC/DEC n. } \\
02 / 09\end{array}$ & $\begin{array}{l}\text { Cria o fundo para a implantação da biblioteca UNILA - BIUNILA e do Ins- } \\
\text { tituto MERCOSUL de Estudos Avançados - IMEA, da Universidade Federal } \\
\text { da Integração Latino-Americana - UNILA. }\end{array}$ \\
\hline $\begin{array}{l}\text { MERCOSUL/ } \\
\text { CMC/DEC. n. } \\
29 / 09\end{array}$ & $\begin{array}{l}\text { Apresenta o estado de ratificações e vigências dos tratados e protocolos. } \\
\text { Trata de aprovar os procedimentos e critérios para a implementação do } \\
\text { acordo de admissão de títulos e graus universitários para o exercício de } \\
\text { atividades acadêmicas nos Estados-partes do MERCOSUL. A decisão não } \\
\text { consta da página do MERCOSUL. }\end{array}$ \\
\hline $\begin{array}{l}\text { MERCOSUL/ } \\
\text { CMC/DEC n. } \\
21 / 10\end{array}$ & $\begin{array}{l}\text { Trata do protocolo de integração educativa e reconhecimento de certifica- } \\
\text { dos, títulos e estudos de nível primário/fundamental/básico e médio/secun- } \\
\text { dário entre os Estados-partes do MERCOSUL e os Estados Associados. Tal } \\
\text { protocolo não está ratificado por nenhum Estado. }\end{array}$ \\
\hline $\begin{array}{l}\text { MERCOSUL/ } \\
\text { CMC/ DEC. } \\
\text { n. } 67 / 10\end{array}$ & $\begin{array}{l}\text { No plano estratégico do Mercosul, a decisão MERCOSUL/CMC/DEC. n. } \\
\text { 67/10, em sua } 10^{\mathrm{a}} \text { - diretriz apresenta: "Aumentar a ligação do setor da edu- } \\
\text { cação do Mercosul com outros organismos regionais, os termos quatro ins- } \\
\text { tâncias diferentes, no âmbito da Educação Superior" (MERCOSUL/CMC/ } \\
\text { DEC. n. 67/10, 2010:6). Além da iniciativa de promover educação a distân- } \\
\text { cia para democratizar a Educação Superior, a diretriz 11 } 11^{\text {a }} \text { visa "fortalecer e }\end{array}$ \\
\hline
\end{tabular}




\begin{tabular}{|c|c|}
\hline Documento & Abrangência \\
\hline & $\begin{array}{l}\text { ampliar a abrangência do Sistema de Credenciamento de Cursos de Gra- } \\
\text { duação para o Reconhecimento Regional da Qualidade Acadêmica dos Di- } \\
\text { plomas Universitários do Mercosul (ARCU-SUL)" (MERCOSUL/CMC/ DEC. } \\
\text { n. 67/10, 2010:7, in Brasil, 2013). }\end{array}$ \\
\hline $\begin{array}{l}\text { MERCOSUL/ } \\
\text { CMC/DEC n. } \\
05 / 11\end{array}$ & $\begin{array}{l}\text { Novamente modifica a estrutura orgânica e o regulamento interno da reunião } \\
\text { de ministros da educação e altera os órgãos dependentes do Setor Educa- } \\
\text { cional do MERCOSUL. }\end{array}$ \\
\hline $\begin{array}{l}\text { MERCOSUL/ } \\
\text { CMC/DEC n. } \\
06 / 11\end{array}$ & $\begin{array}{l}\text { Trata de tornar permanente o Fundo de Financiamento do Setor Educacio- } \\
\text { nal do MERCOSUL. A decisão MERCOSUL/CMC/DEC n. 20/11 aprova o } \\
\text { Plano de Ação do Setor Educacional do MERCOSUL 2011-2015. }\end{array}$ \\
\hline $\begin{array}{l}\text { MERCOSUL/ } \\
\text { GMC/RES. n. } \\
16 / 11\end{array}$ & $\begin{array}{l}\text { Trata de um adendo ao convênio de financiamento entre a União Europeia } \\
\text { e o MERCOSUL para o projeto "apoio ao programa de mobilidade MERCO- } \\
\text { SUL em educação superior" - DCI-ALA /2006/18-586, prorrogando o prazo } \\
\text { de vigência do referido projeto. }\end{array}$ \\
\hline $\begin{array}{l}\text { MERCOSUL/ } \\
\text { CMC/DEC n. } \\
18 / 12\end{array}$ & $\begin{array}{l}\text { A decisão trata da adesão da Colômbia ao acordo ARCU-SUR que, como } \\
\text { comentado, ainda não está vigente. }\end{array}$ \\
\hline $\begin{array}{l}\text { MERCOSUL/ } \\
\text { CMC/DEC n. } \\
22 / 12\end{array}$ & $\begin{array}{l}\text { Aprova a adesão do Peru ao protocolo de integração educativa e reconheci- } \\
\text { mento de certificados, títulos e estudos de nível primário e médio não técni- } \\
\text { co entre os estados-partes do MERCOSUL, Bolívia e Chile (BRASIL, 2013). }\end{array}$ \\
\hline $\begin{array}{l}\text { MERCOSUL/ } \\
\text { GMC/RES. n. } \\
39 / 12\end{array}$ & $\begin{array}{l}\text { Aprova o addendum n. } 2 \text { ao convênio de financiamento entre o MERCO- } \\
\text { SUL e a União Europeia denominado "Apoio ao programa de mobilidade } \\
\text { MERCOSUL em Educação Superior - PMM }\end{array}$ \\
\hline $\begin{array}{l}\text { MERCOSUL/ } \\
\text { CMC/DEC. n. } \\
16 / 14\end{array}$ & $\begin{array}{l}\text { Implementa o plano de funcionamento do sistema integrado de mobilidade } \\
\text { do MERCOSUL (SIMERCOSUL), visando ao aperfeiçoamento, ampliação e } \\
\text { articulação de iniciativas de mobilidade acadêmica em educação. }\end{array}$ \\
\hline $\begin{array}{l}\text { MERCOSUL/ } \\
\text { GMC/RES. n. } \\
29 / 14\end{array}$ & $\begin{array}{l}\text { Cria a Unidade Técnica de Educação (UTE), para dar apoio operacional, } \\
\text { administrativo, de coordenação e comunicação ao Setor Educacional do } \\
\text { MERCOSUL, em especial ao SIMERCOSUL. }\end{array}$ \\
\hline $\begin{array}{l}\text { MERCOSUL/ } \\
\text { GMC/RES. n. } \\
17 / 14\end{array}$ & $\begin{array}{l}\text { Completa o conjunto relacionado à Educação, com o addendum n. } 1 \text { ao } \\
\text { convênio de financiamento n. DCI-ALA/2010/19892 MERCOSUL - União } \\
\text { Europeia para o Programa de apoio ao setor educacional do MERCOSUL. }\end{array}$ \\
\hline
\end{tabular}

